\title{
AVALIAÇÃO DE PARÂMETROS MICROBIOLÓGICOS PARA DETERMINAR AS CONDIÇÕES HIGIÊNICO SANITÁRIAS EM PREPARAÇÕES DE "AÇAÍ NA TIGELA" COMERCIALIZADOS EM PRESIDENTE PRUDENTE - SP
}

\author{
Sthefany Regiani Silva, Priscila Campos Lopes, Telma Reginato Martins, Lizziane Kretli Winkelstroter Eller \\ Universidade do Oeste Paulista - UNOESTE, Presidente Prudente, SP. E-mail: lizzianekretli@gmail.com
}

\begin{abstract}
RESUMO
O açaí é considerado um alimento muito nutritivo e atualmente, tem sido bastante consumido na forma de "açaí na tigela". Este trabalho teve como finalidade avaliar a qualidade microbiológica por meio da determinação de Salmonella, Coliformes totais e termotolerantes, Bolores e leveduras a partir da preparação "açaí na tigela" fornecida em uma cidade do Oeste Paulista. Foram coletadas 20 amostras de açaí na tigela de diversos estabelecimentos e em seguida foi realizada a análise microbiológica segundo RDC 12 de 2001. Os resultados deste trabalho demonstraram que cerca de 35\% das amostras analisadas, foram consideradas inadequadas para a quantidade bolores e leveduras. Sete amostras apresentaram valores mínimos para presença de coliformes totais e nenhumas das amostras foram positivas para presença de Salmonella sp., coliformes termotolerantes e Escherichia coli. Destaca- se a importância de se investigar e avaliar as condições encontradas nos alimentos prontos para o consumo, pois falhas nas condições higiênico-sanitárias podem representar um risco potencial à saúde dos consumidores.
\end{abstract}

Palavras-chave: Açaí, contaminação, Salmonella, Escherichia coli, Coliformes, Bolores e leveduras.

\section{EVALUATION OF MICROBIOLOGICAL PARAMETERS TO DETERMINE HYGIENIC-SANITARY CONDITIONS IN "AÇAÍ IN THE BOWL" PREPARATIONS COMMERCIALIZED IN PRESIDENTE PRUDENTE - SP}

\begin{abstract}
Acai is considered a very nutritious food and currently has been widely consumed in the form of "acai in the bowl". The aim of this work was to evaluate the microbiological quality "acai in the bowl" preparation provided in a city of West Sao Paulo. It was collected 20 samples of acai in the bowl from various establishments and then it was performed the microbiological analysis according to RDC 12 de 2001. The results of this study showed that about $35 \%$ of the samples were considered unsuitable for molds and yeasts analyses. Approximately 7 samples presented minimum values allowed for the presence of total coliforms. Moreover, none of the samples were positive for Salmonella spp., Escherichia coli and thermotolerant coliforms. We emphasize the importance of investigating and assessing the conditions found in the food ready for consumption because failures in sanitary conditions may pose a potential health risk to consumers.
\end{abstract}

Keywords: Acai, contaminated, Salmonella spp., Escherichia coli, coliforms, molds and yeasts.

\section{INTRODUÇÃO}

As características organolépticas e as características microbiológicas conceituam a qualidade de um alimento e esse só é considerado seguro quando não oferece perigo à saúde do consumidor ${ }^{1,2}$. 0 controle microbiológico de um alimento processado ou natural é de fundamental importância para garantia da segurança alimentar, pois os alimentos são vulneráveis a contaminação por diversos agentes etiológicos ${ }^{1,3}$.

A presença de micro-organismos em níveis elevados no alimento já processado como - "açaí na tigela" indica a ocorrência de falhas durante a manipulação, armazenamento inadequado, uso de matéria-prima com carga microbiana elevada entre outros ${ }^{4}$. A alta carga microbiana é um dos fatores responsáveis pela deterioração do alimento ${ }^{5,6}$. 
O açaí é considerado um dos alimentos mais nutritivos, sendo excelente fonte de vitamina $E$, fibras, cálcio, magnésio e potássio, além de apresentar uma alta capacidade antioxidante ${ }^{7-9}$. Ele é considerado um alimento funcional, pois é rico em nutrientes e possui características capazes de proteger o nosso organismo contra várias doenças, dentre as propriedades medicinais do açaí inclui a ação anticarcinogênica, antiinflamatória e antimicrobiana, prevenção da oxidação de proteínas de baixa densidade (LDL), enfermidades cardiovasculares e doenças neurológicas ${ }^{10}$.

O consumo do açaí não ocorre na forma in natura, deste modo é necessário seu processamento $^{5}$. A retirada da polpa do fruto é obtida por meio do esmagamento, em seguida, ocorre à filtração com uma peneira fina e a adição de água em quantidades variadas para se obter o chamado "vinho" que pode ter até três diferentes concentrações de acordo com teores de sólidos totais: 15,2 \% (Tipo A), 12,5\% (Tipo B) e 9,7\% (Tipo C). Todo o processo para obtenção da polpa é realizado de forma artesanal e com baixo nível tecnológico, demonstrando o potencial industrial deste setor ${ }^{7,11}$

Por ser um processamento artesanal, muitas vezes não há o cuidado com a higiene na manipulação, na fabricação e pouco se controla os pontos críticos de contaminações. Vários surtos, principalmente nos estado do Pará e Amapá, tem sido associados ao consumo de suco de açaí ${ }^{11-14}$. O principal agente contaminante relacionado a estes surtos é o Tripanossoma cruzi, um protozoário flagelado da família Trypanosomatidae, e agente etiológico da doença de Chagas. De janeiro a outubro de 2007, foram notificados 100 casos de Doença de Chagas Aguda, com 4 óbitos relacionados a surtos ocorridos em 11 municípios da região norte e 12 casos isolados, onde o açaí foi o alimento mais frequentemente envolvido ${ }^{15}$.

O triatomíneo conhecido como barbeiro é o portador deste parasita e normalmente faz ninhos na palmeira do açaí, naquela região. 0 mecanismo de transmissão mais aceito é a contaminação dos frutos por fezes triatomíneos ou a coleta destes insetos parasitados juntamente com a fruta e transportados em cestos e sacos, para as máquinas de extração do suco onde os triatomíneos infectados podem ser esmagados e misturados ao suco. Além disso, uma alta carga microbiana pode estar presente na polpa devido à alta manipulação do fruto na cadeia produtiva e também porque nas regiões produtoras, a polpa normalmente é consumida imediatamente após extração, sendo um produto altamente perecível e de fácil deterioração à temperatura ambiente ${ }^{11-15}$.

Com o aumento do consumo do açaí e o início do processo de industrialização para obtenção das polpas foram adotados novos critérios para evitar a disseminação de doenças como a Doença de Chagas e a sua deterioração. Uma destes critérios é a pasteurização no qual a polpa do açaí é aquecida durante alguns segundos a temperaturas entre $80^{\circ} \mathrm{C}$ e $85^{\circ} \mathrm{C}$, e em seguida é imediatamente resfriada (temperatura que passa de $\left.-30^{\circ} \mathrm{C}\right)^{17}$. Além disso, o Ministério da Saúde (RDC $n^{0} 216$ de 15 de setembro de 2004) recomenda aos produtores artesanais a utilização das técnicas de higienização e branqueamento (imersão em solução de hipoclorito) do fruto do açaí, aliada às boas práticas de coleta, transporte, armazenamento e manipulação, visando minimizar o risco da contaminação do suco ${ }^{11}$.

Atualmente, o açaí tem se tornado popular principalmente entre os esportistas e por aquelas pessoas que buscam uma alimentação saudável, natural e energética, principalmente, por ser um alimento rico em nutrientes e possuir potencial terapêutico. $O$ açaí pode ser consumido de diversas formas: sucos, doces, sorvetes e geleias, entretanto a principal forma consumida no sul e sudeste é o chamado "açaí na tigela". O "açaí na tigela" é uma tradição que começou na praia, foi para as academias e para as ruas. Consiste na polpa da fruta congelada batida no liquidificador e acompanhada de frutas e outros ingredientes como granola, xarope de guaraná, castanhas; normalmente servida em uma tigela $11,17,18$.

A necessidade de refeições rápidas e baratas promoveram o surgimento de uma grande quantidade de bares, quiosques, barracas e restaurantes voltados para a venda de alimentos rápidos, como por exemplo, o "açaí na tigela". A adoção de boas práticas de manipulação do alimento nestes ambientes é de fundamental importância para o consumidor uma vez que minimiza a probabilidade de contaminação microbiológica dos produtos e contribui para a obtenção de um alimento seguro e de qualidade ${ }^{5,17}$. 
Diante desse contexto, fica demonstrado que a segurança alimentar deve ser um requisito fundamental ao longo de toda cadeia produtiva, desde a colheita até a distribuição final ao consumidor. Devido à escassez de dados referentes à qualidade microbiológica do "açaí na tigela" e as condições atuais do fornecimento desta preparação nos pequenos estabelecimentos espalhados em diversos pontos da cidade ressalta-se à importância de se avaliar a qualidade microbiológica destes produtos uma vez que a falha nas condições higiênico-sanitárias pode representar um risco potencial à saúde dos consumidores.

Devido ao risco gerado pelo o consumo de alimentos contaminados e a falta de monitoramento e higiene no preparo destes alimentos foi realizado este estudo cujo objetivo foi determinar a qualidade microbiológica de "açaí na tigela" comercializados na cidade de Presidente Prudente-SP por meio da quantificação de coliformes totais, termotolerantes, aeróbios mesófilos, E. coli, Salmonella, bolores e leveduras uma vez que esses parâmetros estão vinculados a aplicação de práticas higiênico-sanitárias durante o preparo do alimento.

\section{METODOLOGIA}

A preparação "açaí na tigela" não possui parâmetros específicos nos padrões microbiológicos vigentes, na Resolução RDC $\mathrm{n}^{\circ} 12$ de 02 de janeiro de 2001 da ANVISA ${ }^{11}$. Portanto, foi utilizado os padrões que estabelece normas para "Sucos, refrescos, refrigerantes e outras bebidas não alcoólicas, excluindo os de base láctea e de chocolate (cacau e similares)" onde estabelece a necessidade da identificação e quantificação de Coliformes totais e termotolerantes, de Salmonella sp. além da quantificação de bolores e leveduras.

Foram obtidas um total de 20 amostras de "açaí na tigela" suplementado com frutas (banana ou morango) em diferentes quiosques e lanchonetes do comércio local de Presidente Prudente - SP. Para a análise microbiológica, foram coletados cerca de $100 \mathrm{~mL}$ de cada preparação, sendo armazenada em condições assépticas, dentro de sacos plásticos esterilizados e transportada até o laboratório de microbiologia para as análises.

Segundo o Food and Drug Administration $^{21}$, para a quantificação dos micro- organismos foram utilizados $25 \mathrm{~g}$ de cada amostra de açaí na tigela, em seguida o material foi diluído em $225 \mathrm{~mL}$ de água peptonada a $0,1 \%$ esterilizada e posteriormente homogeneizados, obtendo-se assim a diluição de $10^{-1}$. A partir dessa diluição, foram feitas diluições em série até a obtenção da diluição $10^{-5}$. O método de contagem de bolores e leveduras consistiu na semeadura em ágar batata dextrose (PDA) pela técnica de semeadura em superfície. As placas foram incubadas por 5 dias a $22^{\circ} \mathrm{C}^{20,21}$.

As mesmas diluições foram utilizadas para a semeadura em ágar padrão de contagem para determinação de aeróbios mesófilos. As placas foram incubadas a $37^{\circ} \mathrm{C}$ por $48 \mathrm{~h}^{20,21}$.

A pesquisa de Salmonella sp. foi realizada com um pré-enriquecimento em água peptonada tamponada $\left(24 \mathrm{~h}\right.$ a $\left.37^{\circ} \mathrm{C}\right)$ e enriquecimento seletivo em Caldo Rappaport-vassiliadis ( $24 \mathrm{~h}$ a $42^{\circ} \mathrm{C}$ ) e Caldo Tetrationato $\left(24 \mathrm{~h}\right.$ a $\left.37^{\circ} \mathrm{C}\right)$, seguida por semeadura em ágar XLD e Hektoen-enteric (HE), sendo ambos incubados por $24 \mathrm{~h}$ a $37^{\circ} \mathrm{C}$. Colônias típicas foram submetidas à identificação bioquímica em Ágar Tríplice Ferro, Ágar Lisina Ferro e Ágar Urease $\left(24 \mathrm{~h} \text { a } 37^{\circ} \mathrm{C}\right)^{20,21}$.

As diluições utilizadas para pesquisa de bolores e leveduras também foram utilizadas para verificar a presença de coliformes totais e termotolerantes. Uma alíquota de cada diluição foi semeada em tubos contendo Caldo verde brilhante 2\% (VB) contendo tubos de Durhan invertidos para o crescimento de coliformes totais. Além disso, foram inoculados tubos contendo caldo Escherichia coli (E.C.), meio confirmatório para coliformes termotolerantes (E.C.) e deixados em banho-maria de 44,5 a $45^{\circ} \mathrm{C}$ durante $24 \mathrm{~h}$. A positividade do teste foi observada pela produção de gás no interior dos tubos de Durhan. O número de coliformes totais e termotolerantes foram obtidos na tabela de Número Mais Provável (NMP), baseado no número de tubos positivos do caldo Verde Brilhante (VB) e de caldo Escherichia coli (E.C.) respectivamente, sendo os resultados expressos em NMP/100 mL ${ }^{20,21}$.

Dos tubos positivos para o meio E.C. alíquotas foram semeadas em placas de Petri contendo meio de cultura ágar eosina azul de metileno (EMB) e posteriormente incubadas de 35 a $37^{\circ} \mathrm{C}$ por $24 \mathrm{~h}$. Por fim, a caracterização dos coliformes termotolerantes foi evidenciada pelo crescimento de colônias com centros enegrecidos e brilho verde metálico ${ }^{20,22}$. 
Os experimentos foram realizados em triplicatas e para análise estatística será utilizado o teste ANOVA (Bonferroni), considerando significativo $\mathrm{P}<0,01$. Os dados foram analisados com o software Prisma (GrafPad Software).

\section{RESULTADOS}

No presente trabalho foi analisada a contaminação microbiológica de 20 amostras de açaí na tigela com diferentes ingredientes conforme demonstrado na Tabela 1. As amostras foram coletadas em 5 estabelecimentos diferentes entre eles, lanchonetes de uma faculdade e da região central da cidade e quiosque de um shopping. O período de coleta foi de novembro a dezembro de 2015.

Tabela 1. Descrição dos ingredientes do açaí na tigela e estabelecimento onde foi coletado.

\begin{tabular}{ccc}
\hline $\mathbf{N}^{\circ}$ mostra & Composição do açaí na tigela & Estabelecimento \\
\hline 1 & Açaí com morango & $\mathrm{A}$ \\
2 & Açaí com morango & $\mathrm{A}$ \\
3 & Açaí com morango & $\mathrm{A}$ \\
4 & Açaí com morango & $\mathrm{A}$ \\
5 & Açaí com morango & $\mathrm{B}$ \\
6 & Açaí com morango & $\mathrm{B}$ \\
7 & Açaí com morango & $\mathrm{B}$ \\
8 & Açaí com morango & $\mathrm{B}$ \\
9 & Açaí com banana & $\mathrm{C}$ \\
10 & Açaí com banana & $\mathrm{C}$ \\
11 & Açaí com banana & $\mathrm{C}$ \\
12 & Açaí com banana & $\mathrm{C}$ \\
13 & Açaí com banana granola leite ninho leite condensado & $\mathrm{D}$ \\
14 & Açaí com banana granola leite ninho leite condensado & $\mathrm{D}$ \\
15 & Açaí com banana granola leite ninho leite condensado & $\mathrm{D}$ \\
16 & Açaí com banana granola leite ninho leite condensado & $\mathrm{D}$ \\
17 & Açaí com morango & $\mathrm{E}$ \\
18 & Açaí com morango & $\mathrm{E}$ \\
19 & Açaí com morango & $\mathrm{E}$ \\
20 & Açaí com morango & $\mathrm{E}$ \\
\hline
\end{tabular}

Foi avaliada a contaminação das amostras de açaí na tigela em relação a aeróbios mesófilo. De acordo com os resultados (Tabela 2) foi observado que as contagem variaram de no mínimo 2,38 $\pm 0,12$ UFC/g (Açaí com banana) a um máximo de 6,7 $\pm 0,00 \mathrm{UFC} / \mathrm{g}$ (Açaí com morango). Além disso, foi observada variação nas contagens de bolores e leveduras de 2,30 $\pm 0,42$ log UFC/g (Açaí com banana) a um máximo de $5,87 \pm 0,02 \log$ UFC/g (Açaí com morango) (Tabela 2).

Com os resultados obtidos neste trabalho foi possível observar um mínimo de contaminação por coliformes totais ( $<3 \mathrm{NMP} / \mathrm{g}$ de açaí na tigela) em cerca de 7 amostras e apenas uma com > $1100 \mathrm{NMP} / \mathrm{g}$.
A análise da contaminação das amostras com Salmonella sp, coliformes termotolerantes e Escherichia coli apresentaram resultados negativos, demonstrando ausência destes microorganismos em $25 \mathrm{~g}$ de alimento analisado. 
Tabela 2. Quantificação de aeróbios mesófilos, bolores e leveduras, Salmonella sp, coliformes totais e termotolerantes, Escherichia coli em amostras de açaí na tigela comercializados na cidade de Presidente Prudente.

\begin{tabular}{|c|c|c|c|c|c|c|}
\hline Amostra & $\begin{array}{l}\text { Aeróbios } \\
\text { mesófilos } \\
\text { (UFC/g) }\end{array}$ & $\begin{array}{c}\text { Bolores e } \\
\text { leveduras } \\
\text { (UFC/g) }\end{array}$ & $\begin{array}{c}\text { Salmonella sp. } \\
\text { (UFC/g) }\end{array}$ & $\begin{array}{c}\text { Coliformes } \\
\text { totais } \\
(\mathrm{NMP} / \mathrm{g})\end{array}$ & $\begin{array}{c}\text { Coliformes } \\
\text { Termotolerantes } \\
\text { (NMP/g) }\end{array}$ & $\begin{array}{c}\text { Escherichia } \\
\text { coli }\end{array}$ \\
\hline 1 & $3,46 \pm 0,14$ & $3,74 \pm 0,043$ & Ausente & 3,6 & Ausente & Ausente \\
\hline 2 & $3,53 \pm 0,10$ & $4,06 \pm 0,03$ & Ausente & $<3$ & Ausente & Ausente \\
\hline 3 & $3,39 \pm 0,07$ & $4,32 \pm 0,10$ & Ausente & $<3$ & Ausente & Ausente \\
\hline 4 & $3,46 \pm 0,23$ & $4,27 \pm 0$ & Ausente & 3 & Ausente & Ausente \\
\hline 5 & $4,78 \pm 0,12$ & $4,78 \pm 0,12$ & Ausente & 23 & Ausente & Ausente \\
\hline 6 & $4,64 \pm 0,04$ & $4,64 \pm 0,04$ & Ausente & 23 & Ausente & Ausente \\
\hline 7 & $5,37 \pm 0,14$ & $5,37 \pm 0,14$ & Ausente & 93 & Ausente & Ausente \\
\hline 8 & $5,87 \pm 0,02$ & $5,87 \pm 0,02$ & Ausente & 9,2 & Ausente & Ausente \\
\hline 9 & $2,38 \pm 0,12$ & $2,45 \pm 0,21$ & Ausente & $<3$ & Ausente & Ausente \\
\hline 10 & $2,81 \pm 0,04$ & $2,58 \pm 0,15$ & Ausente & 3,6 & Ausente & Ausente \\
\hline 11 & $2,84 \pm 0,08$ & $2,30 \pm 0,42$ & Ausente & $<3$ & Ausente & Ausente \\
\hline 12 & $3,38 \pm 0,12$ & $3,07 \pm 0,10$ & Ausente & $<3$ & Ausente & Ausente \\
\hline 13 & $4,29 \pm 0,16$ & $*$ & Ausente & $<3$ & Ausente & Ausente \\
\hline 14 & $3,66 \pm 0,09$ & $2,77 \pm 0,42$ & Ausente & $<3$ & Ausente & Ausente \\
\hline 15 & $4,07 \pm 0,36$ & $*$ & Ausente & 23 & Ausente & Ausente \\
\hline 16 & $4,72 \pm 0,07$ & $*$ & Ausente & 23 & Ausente & Ausente \\
\hline 17 & $6,22 \pm 0,10$ & $3,65 \pm 0,23$ & Ausente & 23 & Ausente & Ausente \\
\hline 18 & $5,70 \pm 0,06$ & $4,49 \pm 0,01$ & Ausente & 446 & Ausente & Ausente \\
\hline 19 & $6,7 \pm 0,00$ & $5,15 \pm 0,03$ & Ausente & 36 & Ausente & Ausente \\
\hline 20 & $4,75 \pm 0,03$ & $5,18 \pm 0,26$ & Ausente & $>1100$ & Ausente & Ausente \\
\hline
\end{tabular}

*Valor abaixo do limite de detecção $<30$ UFC/g. 


\section{DISCUSSÃO}

O consumo do açaí veio (vem) crescendo nos últimos anos e a sua popularização se deve principalmente por ser um alimento com caráter energético e nutritivo. $O$ açaí é consumido de uma forma variada, entretanto na região de Presidente Prudente ele é consumido principalmente como bebida energética, na forma de "açaí na tigela"

O grande risco no consumo do "açaí na tigela" se deve a sua grande manipulação deste a sua colheita até a produção da polpa. Além disso, devem ser observadas as condições higiênicosanitárias dos equipamentos, ambiente de processamento e dos manipuladores, pois estas favorecem a presença de uma alta carga microbiana e podem resultar em doenças transmitidas por alimentos ${ }^{5,22,23}$.

A finalidade de se detectar bactérias aeróbias é avaliar de uma maneira geral o grau de contaminação e as condições higiênicas daquele alimento. De acordo com Faria et al. ${ }^{5}$ uma amostra com cerca de 5 log UFC/g de alimento é considerado um produto em condições higiênicas insatisfatórias. Se este valor for $6 \log \mathrm{UFC} / \mathrm{g}$, o alimento é considerado inaceitáveis para o consumo direto e acima de 7 log UFC/g o consumo é impróprio. De acordo com estes padrões podemos observar pelos resultados obtidos durante o estudo que o total de $25 \%$ das amostras analisadas não estão apropriadas para consumo quando o parâmetro observado são as contagens de aeróbios mesófilo, pois 3 amostras são consideradas insatisfatórias, e 2 amostras apresentaram condições inaceitáveis para 0 consumo direto $(P<0,001)$.

Não há padrões vigentes para o máximo permitido de bolores e leveduras em amostras de açaí na tigela. Entretanto, o Ministério de Agricultura e do Abastecimento, regulamentou os padrões de identidade e as características mínimas de qualidade gerais para polpas de frutas e estabeleceu $2 \times 10^{3}$ UFC. $g^{-1}$ de bolores e leveduras, para polpa conservada quimicamente e/ou que sofreu tratamento térmico ${ }^{23}$. Baseando os resultados nos padrões determinados para polpas de frutas, obteve-se o total de 13 (cerca de $65 \%$ - $P<0,001$ ) amostras apresentaram valores acima do sugerido pela legislação, assim, se faz importante salientar que os ingredientes adicionados nas preparações levam a dúvida quanto suas condições sanitárias, propondo uma possível fonte contaminadora para o açaí no momento do preparo.

Os micro-organismos indicadores são comumente utilizados para avaliar as condições higiênicas de alimentos; sua presença evidencia relação com o histórico da amostra. A presença de coliformes totais esta relacionada a práticas inadequadas de sanitização e processamento, ou mesmo à recontaminação, dos alimentos após esses procedimentos. Apesar de não estar estabelecido limite máximo de coliformes totais pelos órgãos competentes, esta constatação indica falta de condições higiênicas adequadas em alguma etapa da cadeia produtiva do açaí na tigela em alguns estabelecimentos ${ }^{14}$.

A quantificação de coliformes termotolerantes indica provável contato fecal, nesta ocasião a $E$. coli é o micro-organismo de escolha como indicador, uma vez que é de fácil isolamento nos meios de cultura convencional e mais resistente por um período de tempo maior $^{14}$. A RDC n. 12, de 02/01/2001, estabelece valor máximo de $10^{2}$ UFC. $g^{-1}$ para coliformes termotolerantes o que representa cerca de 2 log UFC/g. A análise da contaminação das amostras com coliformes termotolerantes e Escherichia coli apresentaram resultados negativos, demonstrando ausência deste micro-organismo em $25 \mathrm{~g}$ de alimento analisado.

A análise da contaminação das amostras com Salmonella sp apresentaram resultados negativos, demonstrando ausência deste microorganismo em $25 \mathrm{~g}$ de alimento analisado.

Foi possível observar também que o estabelecimento $\mathrm{C}$ apresentou melhores condições higiênico-sanitária, pois apresentou as menores quantificações de micro-organismos indicadores. Cohen et al. $^{26}$ analisaram a qualidade sanitária da polpa de açaí em dez pontos de comercialização da cidade de Belém, $\mathrm{PA}$, entre eles quatro supermercados, duas feiras livres e quatro pontos de venda ("batedeiras"). Das dez amostras analisadas, todas apresentaram coliformes fecais e fungos filamentosos e leveduras e em duas amostrass foi verificada a presença de Salmonella. Cayres et al. ${ }^{27}$ realizaram a avaliação microbiológica em 48 amostras de açaí tipo fino, congelado, puro e não pasteurizado. De acordo com os resultados foi encontrado ausência de Salmonella e E. coli em todas as amostras analisadas. Já para as análises de bolores e leveduras, $15 \%$ das amostras estavam em desacordo com os valores aceitos 
pela legislação. Este dado pode ser um indicativo de práticas inadequadas durante a fabricação do açaí.

Faria et al. ${ }^{5}$ avaliou a qualidade microbiológica de polpas de açaí comercializadas em cidade de Pouso Alegre - MG. Foram analisadas 36 amostras de polpas de açaí congeladas, destas amostras, $75 \%$ encontravamse acima dos valores estabelecidos pela legislação para contagem de coliformes totais, $16,7 \%$ das amostras apresentaram coliformes termotolerantes acima do permitido e 13,8\% confirmaram presença de Escherichia coli. Também foram observadas contagens de bolores e leveduras fora dos padrões estabelecidos em $8,3 \%$ das amostras. Jones et al. ${ }^{23}$ investigaram a contaminação em polpas pasteurizadas de açaí, embaladas à granel e embaladas individualmente. Nenhuma das amostras apresentaram crescimento para Salmonella sp. entretanto, todas apresentaram altos níveis e aeróbios mesófilos e crescimento de bactérias do grupo coliformes fecal (tanto embaladas a granel ou individualizadas). Os resultados destes trabalhos demonstraram que as polpas de açaí pasteurizadas e congeladas apresentaram em sua maioria baixa qualidade higiênico-sanitária, provavelmente devido a falhas higiênicas durante o processamento e manipulação do produto.

Eto et al. ${ }^{22}$ avaliaram polpas e mix de açaí após congelamento por $0,3,6$ e 9 meses. Todas as amostras de diferentes marcas e tempo de armazenamento demonstraram ausência de Salmonella, coliformes totais e fecais indicando que as amostras analisadas apresentaram conformidade com a legislação no aspecto higiênico sanitário. Cardonha et al. ${ }^{25}$ avaliaram preparação "açaí na tigela" contendo polpa de açaí e xarope de guaraná. Foram adquiridas cinco amostras em quatro diferentes pontos de comercialização na zona sul da cidade de Natal RN e realizadas análises para coliformes fecais a $45^{\circ} \mathrm{C}$, pesquisa de Salmonella e contagem de bolores e leveduras. Segundo aqueles autores no que se refere a coliformes fecais e bolores e leveduras foram encontrados $5 \%$ das amostras com crescimento microbiano acima do limite estabelecido pela legislação, entretanto em relação à Salmonella sp. foi observada ausência de crescimento, portanto, em concordância com a legislação.

A negligência em segurança alimentar é um problema de Saúde Pública e pode gerar uma série de consequências entre elas doenças transmitidas por alimentos. No presente trabalho, as amostras analisadas para parâmetros microbiológicos como presença de coliformes termotolerantes, Salmonella sp e Escherichia coli apresentaram resultados negativos, devido ao nível reduzido de amostras. Quanto à contaminação por coliformes totais, bolores e leveduras foi observado que as condições higiênica-sanitária de alguns estabelecimentos ainda não estão adequadas para o preparo de alimentos. Contudo, novas analises devem ser realizadas e a adoção de um programa de educação continuada dos manipuladores de açaí na tigela é desejável para que sejam aplicadas medidas preventivas para se evitar a contaminação dos alimentos.

\section{AGRADECIMENTOS}

Os autores agradecem o apoio financeiro fornecido pela UNOESTE processo n ${ }^{\circ} 2813$ e 2814.

\section{DECLARAÇÃO DE CONFLITO DE INTERESSE}

Os autores declaram não haver qualquer conflito de interesse que possa interferir na imparcialidade deste trabalho científico.

\section{REFERÊNCIAS}

1. Alencar AG. Do conceito estratégico de segurança alimentar ao plano de ação da FAO para combater a fome. Rev Bras Polít Int. 2001;44:137-44. DOI: https://doi.org/10.1590/S0034-73292001000100009

2. Cunha FMF, Magalhães MBH, Bonnas DS. Desafios da gestão da segurança dos alimentos em unidades de alimentação e nutrição no Brasil: uma revisão. Acesso em 8 jul 2015. Disponível em: http://www.revistas.sp.senac.br/index.php/revistacon textos/article/viewFile/394/332

3. Franco BDGM, Landgraf M. Microbiologia de Alimentos. São Paulo: Atheneu; 1996.

4. Clemente ES. Controle higiênico-sanitário em supermercados. $5^{\circ}$ Congresso Nacional de Higienistas de Alimentos. Foz do Iguaçu - PR, 1999.

5. Faria M, Oliveira LBD, Costa FEC. Determinação da qualidade microbiológica de polpas de açaí congeladas comercializadas na cidade de Pouso Alegre - MG. Alim Nutr. 2012;23:243-9.

6. Oliveira ENS, Santos DC. Processamento e avaliação da qualidade de licor de açaí (Euterpe oleracea Mart.). Rev Adolfo Lutz. 2011;70:534-41. 
7. Pereira EA, Quieroz AJM, Figueirêdo RMF. Massa específica de polpa de açaí em função do teor de sólidos totais e da temperatura. Rev Bras Eng Agríc Ambiente. 2001;6:526-30.

8. Udani JK, Singh BB, Singh VJ, Barrett ML. Effects of Açai (Euterpe oleracea Mart.) berry preparation on metabolic parameters in a healthy overweight population: a pilot study. Nutr J. 2011;12:1-7. DOI: https://doi.org/10.1186/1475-2891-10-45

9. Yuyama LKO, Aguiar JPL, Silva Filho DF, Yuyama K, Varejão MJ, Fávaro DIT, Vasconcellos MBA, Pimentel AS, Caruso MSF. Caracterização físico-química do suco de açaí de Euterpeprecatoria Mart. oriundo de diferentes ecossistemas amazônicos. Acta Amaz. 2014;41:545-52.

DOI:

https://doi.org/10.1590/S0044-59672011000400011

10. Bonomo LF, Silva, DN, Boasquivis PF, Paiva FA, Guerra JFC, Martins TAF, Torres AGJ, Paula ITBR. Acal' (Euterpe oleracea Mart.) Modulates oxidative stress resistance in Caenorhabditis elegansby direct and indirect mechanisms. PLOS One. 2014;9:1-15. DOI: https://doi.org/10.1371/journal.pone.0089933

11. Agencia Nacional de Vigilância Sanitária - ANVISA 2008 - Informe Técnico no 35, de 19 de junho de 2008 assunto: Gerenciamento do Risco Sanitário na Transmissão de Doença de Chagas Aguda por Alimentos. Acessado em: 7 jul 2015. Disponível em: http://portal.anvisa.gov.br/wps/portal/anvisa/anvisa/ho me/alimentos/!ut/p/c4/04_SB8K8xLLM9MSSzPy8xBz 9CP0os3hnd0cPE3MfAwMDMydnA093Uz8z00B_A3 cvA 2CbEdFADQgSKI!/?1dmy\&urile=wcm\%3Apath \%3A/anvisa+portal/anvisa/inicio/alimentos/publicacao +alimentos/informes+alimentos/2008-06-19-35

12. Xavier SCC, Roque ALR, Bilac D, Araújo VAL, Costa Neto SF, Lorosa ES, Silva LFCF, Jansen AM. Distant e Transmission of Trypanosoma cruzi: A new epidemiological feature of acute chagas disease in Brazil. PLOS Neglec Trop Diseas, 2014;8:1-8. DOI: https://doi.org/10.1371/journal.pntd.0002878

13. Souza-Lima RC, Barbosa MGV, Coura JR, Arcanjo ARL, Nascimento AS, Ferreira JMB, Magalhães LK, Albuquerque BC, Araújo GAN, Guerra JAO. Outbreak of acute Chagas disease associated with oral transmission in the Rio Negro region, Brazilian Amazon Rev. Soc Bras Med Trop. 2013;46:510-514. DOI: https://doi.org/10.1590/0037-8682-1367-2013

14. Sousa CP. Segurança alimentar e doenças veiculadas por alimentos: utilização do grupo coliforme como um dos indicadores de qualidade de alimentos. Revista APS. 2006;9:83-8.
15. Fregonesi BM, Yokosawa CE, Okada IA, Massafera G, Costa TMB, Prado SPT. Polpa de açaí congelada: características nutricionais, físico-químicas, microscópicas e avaliação da rotulagem. Rev. Inst. Adolfo Lutz. 2010;69(3):387-95.

16. Empresa Brasileira de Pesquisa AgropecuáriaEMBRAPA, 2015. Acesso em: 7 jul 2015. Disponível em:

http://www.agencia.cnptia.embrapa.br/gestor/acai/arvo re/CONT000gbfbxyh102wx5ok07shnq9fmqapzn.html

17. Guimarães LAC. O açaí já "parou" o carioca? estudo qualitativo do consumo da polpa de açaí na cidade do Rio de Janeiro. Paper do NAEA 090. 1998;120. Acesso em: 7 jul 2015. http://www.conab.gov.br/OlalaCMS/uploads/arquivos/

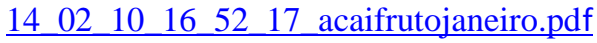

18. Izac JD. Açaí na tigela. Conversa Pessoal Ano VI. 2006;70. Acesso: 5 jul 2015. Disponível em: http://www.senado.gov.br/senado/portaldoservidor/jorn al/jornal70/nutricao_acai.aspx

19. Brasil 2001. Agência Nacional de Vigilância Sanitária. Resolução RDC, n. 12 de 2 de janeiro de 2001. Aprova o regulamento técnico sobre padrões microbiológicos para alimentos. Diário Oficial da União, Brasília, Seção 1. Acesso em: 5 jul 2015. Disponível

em: http://portal.anvisa.gov.br/wps/wcm/connect/a47bab80 47458b909541d53fbc4c6735/RDC_12_2001.pdf?MO D=AJPERES

20. American Public Health Association. Compendium of methods for the microbiological examination of foods. 4.ed. Washington, 2001.

21. Food and Drug Administration - FDA. Bacteriological analytical manual, 7th end AOAC International, Arlington, Virginia, 1992.

22. Eto DK, Kano AK, Borges MTMR, Brugnaro C, Antonini SRC, Bernardi MRV. Qualidade microbiológica e físico-química da polpa e mix de açaí armazenada sob congelamento. Rev Inst Adolfo Lutz. 2010;69:30410.

23. Jones LC, Lemes RLM. Análise microbiológica de polpas de açaí comercializadas em uma cidade do sul de Minas Gerais. Rev Univers Vale do Rio Verde. 2014;12:601-8.

DOI:

https://doi.org/10.5892/ruvrd.v12i2.1509

24. Brasil. 2000. Ministério da Agricultura do Abastecimento. Instrução normativa n. 01/00, de 07/01/00. Dispõe sobre regulamento técnico geral para fixação dos padrões de identidade e qualidade 
para polpa de fruta. Diário Oficial República Federativa do Brasil, Brasília, DF, 10 jan. 2000, Seção 1: 54-58.

25. Cardonha MAS, Diniz LOA, Holland N. Avaliação Microbiológica da Preparação "Açaí na Tigela" comercializada na cidade de Natal - RN. V Congresso Latino Americano e XI Congresso Brasileiro de Higienistas de Alimentos. 2011.

26. Cohen KO, Matta VM, Furtado AAL, Medeiros NL, Chisté RC. Contaminantes microbiológicos em polpas de açaí comercializadas na cidade de Belém-PA. Univers Tecnol Fed Paraná - UTFPR Campus Ponta Grossa - Paraná. 2011;5:524-30. DOI: https://doi.org/10.3895/S1981-36862011000200004

27. Cayres CA, Penteado AL, Pereira KS, Soares C. M. Avaliação microbiológica de polpa de açaí congelada comercializada na cidade do Rio de Janeiro. In: Anais do Simpósio em Ciência e Tecnologia de Alimentos e $2^{\circ}$ Congresso do Instituto Nacional de Frutos Tropicais. Avanços em tecnologia de alimentos, Universidade Federal de Sergipe, Aracajú. 2010.

Recebido para publicação em 25/03/2017

Revisado em 24/11/2017

Aceito em 07/05/2018 